\section{Dr. Sims' Perseverance.}

West Union, Iow A, April 24, 1896.

To the Editor:-In the address of Dr. Jelks in our Jocr s.L April 18, there is clearly a misprint. I think this should be corrected in justice to the memory of Dr. J. Marion Sims. It furnishes stronger proof of the patient perseverance of this truly great man, and evidences his wonderful power to inspire confidence in his patients, as well as all who came in close relation with him.

In the eighth line from the bottom of the first column, on page 752, the word "thirteenth" I think should read thirtieth. In 1876, when president of the AMERICAN MEdical AssociaTION in Philadelphia, he reported the tediousness of his efforts to perfect an operation for the cure of vesico-vaginal fistula, and remarked that the young colored woman mounted the operating table hopefully the thirtieth time. On page 52 of the "Report of Columbia Hospital for Women," by J. Harry Thompson, A.M., M.D., Government printing office, 1873, you will find the same statement, in an address delivered before the Academy of Medicine, New York, by Dr. Sims. Let Dr. Sims have all the honor-none can be too great- for his patient perseverance, and his ability to inspire hope and courage, as indicated by the fact that his patient was "placed upon the operating table the thirtieth time," instead of the thirteenth, without a murmur at "preceding failures." To any who personally knew Dr. Sims, or had met him occasionally, any matter to his credit would merit all the amplitude possible.

$$
\text { Fraternally, S. E. Robrisox, M.D. }
$$

\section{A Correction.}

Minnearolis, April 19, 1896.

To the Editor:--In your report of the proceedings of the Tri-State Medical Society, in your last issue, I am so grossly misrepresented in what I said, that I must beg you to place this brief correction in your next issue.

The title of my paper was "The Relationship Existing Between Oculists and Opticians." You quote me as saying that I "advanced strong arguments in favor of licensing opticians to fit glasses." Had you said "dispense" instead of " fit," you would have expressed my sentiments. There is as much difference between dispensing and fitting glasses, as there is between dispensing and prescribing medicine; and the optician should occupy the same relation to an oculist, that a druggist does to the general and special medical practitioner, viz., a preparer and dispenser of specified remedies (glasses), upon the receipt of a physician's (oculist's) written prescription.

I claim that correcting errors of refraction is practicing med icine, and that no one should be allowed to practice any department of medicine, including refraction, unless he is a properly qualified, licensed graduate in medicine. I also advocate that as in most States, a druggist can only compound prescriptions after having obtained a pharmaceutic license, so opticians should only be allowed to dispense glasses when permitted to do so by a "State Board of Opticians" to be appointed by the governors of the different States.

Respectfully,

Frank Allport, M.D.

"A Credit to America."

Wisiper, April 22, 1896.

The Jorrval is improving every week-a credit to America Yours faithfully,

M. B. Fercieson, M.D.

Total Extirpation of the Protsate Gland and Rectnm.-Salischev describes in Wratch No. 2, the removal of the lower third of the rectum and the prostate gland on account of a scirrhous eancer, the fifth operation of the kind on record. The patient made a fine recovery but succumbed four months later to a meningo-myelitis. The necropsy showed that the operation weund had healed completely.-Bulletin. Médical, April 5.

\section{NEW INSTRUMENTS.}

\section{A COMPLETE SET OF CURETTES FOR MASTOID AND} MIDDDE EAR OPERATIONS.

BY s. S. BISHOP, M.D., OF CHICACOO.

The illustration shows six curettes and spoons conveniently arranged in the form of three instruments. They are all-sharp except one that I have had left dull for work in the immediate vicinity of the facial nerve.

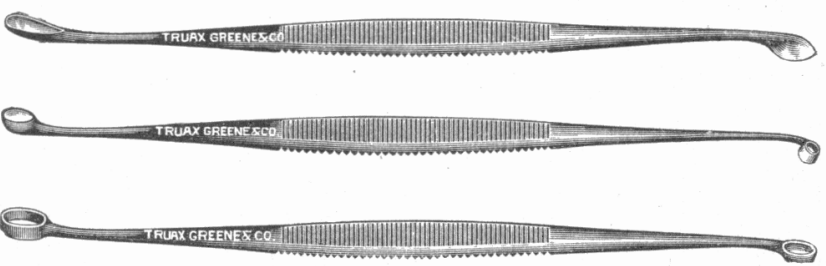

The smallest one is my middle ear curette. The others are the sizes and forms I have found to be the most serviceable in the mastoid operations. It is a considerable advantage to have all the curettes we require within the compass of three instruments. It saves valuable time in selecting the various instruments as we proceed, and these all having the same general appearance, the eye recognizes them at a glance. The handles are flattened and roughened so as not to slip or turn easily. They will be found useful in other operations requiring curettes. They are fine specimens of the workmanship of Truax, Greene \& Co.

\section{PUBLIC HEALTH.}

Enforcement of Registration Laws in Connecticut.-The last Bulletin of the State Board of Health reports that steps are being taken in the State to compel physicians to make more complete returns of the births. It says: "The habitual neglect of obeying the registration laws in regard to the reporting of births, by so many physicians, has driven the authorities to take peremptory action. The Health officer of New Haven County gave a list of delinquents last month to the prosecuting attorney. The latter, in a spirit of leniency which he says will not continue, refrained from prosecuting the law-breakers, but wrote them each a warning that future complaints would be vigorously investigated and liabilities enforced. The Health officer of Fairfield County, caused the arrest of a prominent practitioner in Stamford, last month. In his case too, the court suspended judgment with an intimation that his future conduct would determine further proceedings. At a meeting of the County Health officers held in Hartford on April 4, it was voted : That in future an examination of all the certificates of births, marriages and deaths would be made and whenever a violation of the law was found, the name of the offending party will be given to the prosecuting attorney of the town in which the offence is committed. The certificates themselves are evidence, as the registrar is required to endorse on them the date of their return. In the hope of promoting more successfully the above intention, a circular letter has been prepared and sent to the physicians, setting forth the objects of the registration laws and their weighty importance to the public interest. Among other things, this circular says: 'The main purpose of the registration of vital statistics is to furnish to the public a reliable means of tracing relationship, upon which depends matters of inheritance, descent of property, pension rights, etc., and to furnish such records as will be reliable and full, years hence, when collateral sources of information have disappeared.' The circular dwells upon the importance of exactness in the statement of particulars. 'Many inaccuracies and abbreviations appear in the certificates, which at first seem to be of little importance, yet when the purpose of the record is considered, it is seen that the certificate is vitiated for the purpose for which 